\title{
GESTÃO DE QUALIDADE PONTO CRUCIAL NA IMPLANTAÇÃO DE PROJETOS EÓLICOS: OS DESAFIOS E OS PONTOS POSITIVOS DA QUALIDADE
}

\author{
Autor: Jeovanez Melo Santiago
}

Artigo de TCC apresentado a Anhanguera (Uniderp/Sobral-CE), na área eólica voltada a gestão de projeto, para obtenção do título de pós graduação em MBA em Gestão de Projetos.

Orientador: Haroldo Mamede Coutinho Simões

\section{RESUMO}

Neste artigo vamos denotar os principais desafios na gestão de projetos na implantação de complexos eólicos visando à gestão de qualidade em si, vindo a priorizar um acompanhamento de todos os processos de qualidade no setor de construção de projetos eólicos. Como também é o resultado de uma pesquisa em que se vivencia e constata evidências que viabilizam o gestor ter todos os pontos rastreados, porém devido inúmeros trabalhos ao longo do andamento do projeto, fica complicado pensar na qualidade e ao fim desse artigo perceberemos uma concepção aberta uma concepção que impacta propriamente a geração de energia ou uma concepção com impactos na geração de energia.

Palavras-chave: gestão de qualidade; gestão de projetos; setor de qualidade;

\section{ABSTRACT}

This paper presents the main challenges in project management and quality processes, with the aim of monitoring all quality processes in the wind project construction sector. It is also the result of a research in which the experience and the constellation that make the manager viable have all the points traced a word that properly impacts power generation or a project with impact on power generation.

Keywords: quality management; project management; quality sector; 


\section{INTRODUÇÃO}

Realizando uma análise de projetos que não tiveram um acompanhamento ativo do setor de qualidade, percebe-se que muitos problemas surgiram antes mesmo da vida útil de cada aero gerador, apesar de termos um custo adicional mais no montante final. A inoperância costuma gerar problemas que inviabilizam demais situações, exemplo paradas inoportunas geram um custo maior para o cliente ou o fornecedor no caso do gestor de implantação ter conseguido rastrear e controlar os pontos que ficaram registrados em documentos e foram gerenciados durante a construção do complexo eólico. Gestão de qualidade somente será viável se o gestor do projeto não se limitar somente na construção deixando esse ponto a parte.

O gerenciamento de projetos tem uma citação fundamental e importante "a maturidade das organizações envolvidas com relação ao sistema de gerenciamento, cultura, estilo e estrutura também podem influenciar no projeto".

Edwards Deming argumenta pontos que sem um rastreio durante todo o processo de implantação de um projeto não vingará se caso não ter uma gestão de qualidade por parte dos stakeholders. O processo de gerenciamento de qualidade também retrata que ao gerenciar a qualidade do projeto requer um plano de qualidade aprovado englobando os principais processos de qualidade definidos. $O$ plano de qualidade é desenvolvido e aprovado durante a fase de planejamento do projeto para confirmar requisitos e padrões da qualidade aplicáveis ao projeto.

O cliente não sabe o que irá acontecer daqui a um, três, cinco anos. Se, na qualidade e apenas um dos seus potenciais fornecedores, esperares até lá para descobrir, dificilmente estarás preparado para o servir (DEMING, 1990, p. x).

Os Stakeholders não sabem o que poderá acontecer nos próximos anos seguintes da implantação do projeto, então o fornecedor vai poder burlar defeitos e problemas que aparecerem, porém com os relatórios do cliente feitos na construção poderão auxiliar ao fabricante para solucionar problemas futuros e presentes e o cliente fica respaldado com a garantia. Todos os conceitos relatados no decorrer do desse artigo se vê com ampla importância para o cliente saber como irá receber seu 
produto, ou seja, produtos nos conformes, padrões e procedimentos corretos de instalação.

\section{ENERGIA EÓLICA}

\subsection{IMPORTÂNCIAS DA ENERGIA EÓLICA E PRINCIPIOS E TECNOLOGIAS}

Energia eólica é a fonte de energia gerada através dos ventos, ouse já, a energia cinética do vento convertida em fontes de energias: mecânica, elétrica dentre outras. Atualmente no Brasil está em plena ascensão e comercialização devido ser uma fonte de renovável e limpa, já em países da Europa a fonte eólica é bastante utilizada como fonte de abastecimento energético chegando a atingir $40 \%$ do fornecimento.

O inicio de adaptação dos cata-ventos para geração de energia
elétrica teve inicio no final do século XIX. Em 1888, Charles F. Brush,
um industrial voltado para eletrificação em campo, ergueu na cidade
de Cleveland, Ohio, o primeiro cata-vento que fornecia $12 \mathrm{~kW}$ em
corrente contínua para carregamento de baterias as quais eram
destinadas, sobretudo, para o fornecimento de energia para 350
lâmpadas incandescentes (SCIENTIFIC AMERICAN, 1890 apud
SHEFHERD, 1994) (RIGHTER, 1991 apud SHEFHERD, 1994).

Os pontos mencionados acima vêm trazendo investimentos de energia eólica no Brasil, em 2010 e 2011 foram leiloados 06 GW de potência e veio aumentando nos últimos anos. Em turbinas eólicas também temos pontos negativos tipo pequeno desmatamento, ruído e avifauna "colisão de aves nas pás do aero gerador", porém a eólica tem um ganho positivo sem a emissão de $\mathrm{CO}^{2}$ a atmosfera como outras fontes de energias as termoelétricas, nucleares e etc. Nas últimas décadas com todo o desenvolvimento da tecnologia o sistema eólico aperfeiçoou algumas necessidades as pás, sistemas automatizados de controle, eixos dentre outras melhorias, assim propiciou mudanças na qual a força motriz dos ventos é convertida em força mecânica e através de um grupo multiplicador de velocidade que geralmente quando no eixo lento dá uma volta de 360 lá no eixo rápido dá em média 90 rotações devido (ao Gear Box) onde é acoplado a um gerador que 
converte toda essa energia cinética/ mecânica em energia elétrica, na qual todo o sistema de energia eólica deve ter certificações de qualidade e acompanhamento de todo o processo de instalação.

\subsection{TIPOS DE AEROGERADORES DE ENERGIA ELÉTRICA}

\subsubsection{ROTOR DE EIXO VERTICAL}

Generalizando o rotor tipo vertical tem uma grande vantagem por não precisar de técnica especial de verificar a direção do vento, que implica na redução do esforço devido as forças inerciais.

Esse modelo vertical se dividem em três tipos Savonius, Darrieus e turbinas com torres de vórtices (escoamento giratório). Georges Jean Marie Darrieus (Toulon, 24 de setembro de 1888 - 15 de julho de 1979) foi um engenheiro aeronáutico francês do século XX. É mais conhecido por sua invenção da turbina eólica Darrieus, uma turbina eólica capaz de operar em qualquer sentido e sob condições meteorológicas adversas. Esse tipo de vertical não se tornou tão comercial devido a evolução de das eólicas de modelo horizontal como se percebese no decorrer deste artigo, hoje no Brasil temos somente aeros horizontais pois tem uma capacidade maior em geração por torre.

Figura 1 - Turbina de eixo vertical. Fonte: Dutra, 2008, pag. 24.

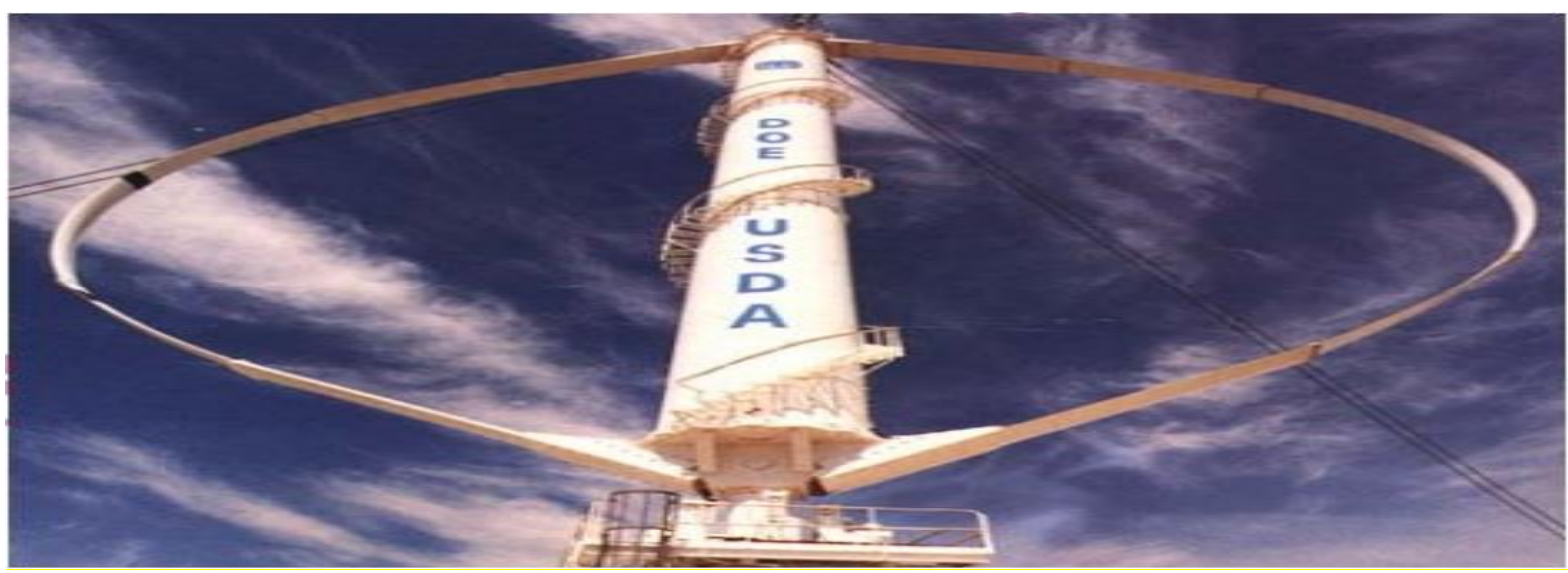




\subsubsection{ROTOR DE EIXO HORIZONTAL}

Generalizando o rotor tipo horizontal é o que mais é comercializado e banal em nosso cotidiano devido o grande avanço tecnológico mundial ter aperfeiçoado os aero geradores de forma eficiente, estes aero geradores tem como fonte as forças aerodinâmicas, ou seja, forças de sustentação são forças que agem perpendicularmente ao fluxo ou a chamada força de arrasto que são forças que agem na direção do escoamento.

Figura 2 - Turbina de eixo horizontal. Fonte: Marques, 2008, pag. 26.
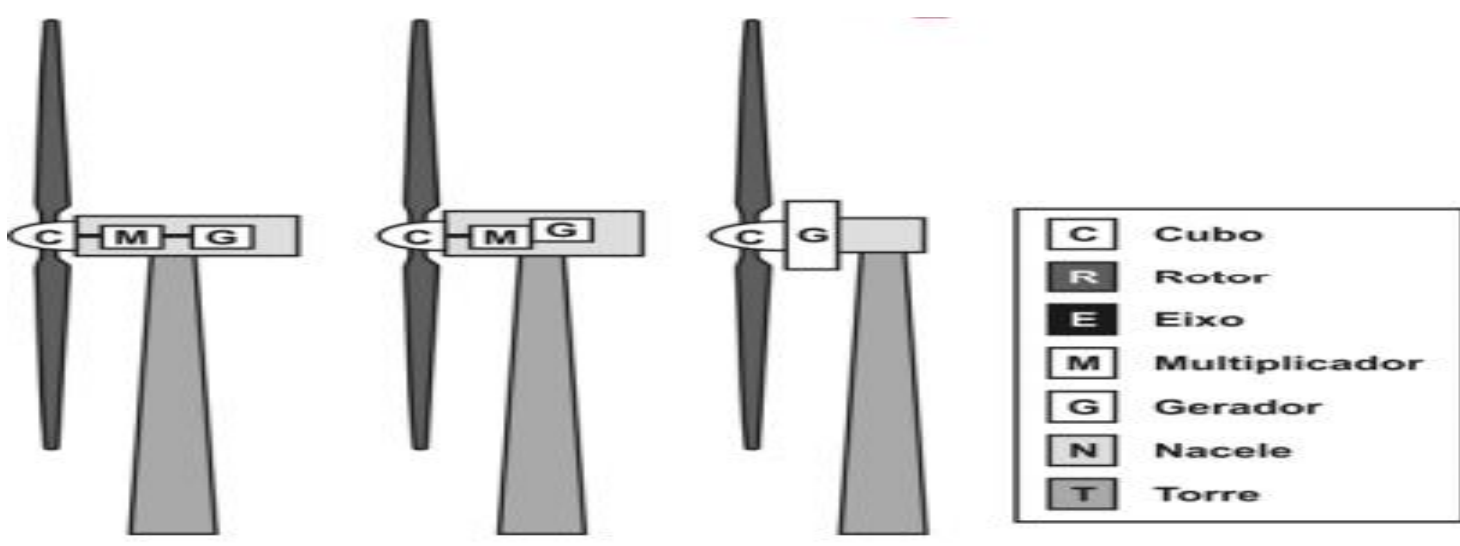

\section{GERENCIAMENTO DE QUALIDADE}

\subsection{PROCESSOS DE GERENCIAMENTO DA QUALIDADE}

Neste tópico se vê os processos de gerenciamento de qualidade defendido por escritores são pontos essenciais: vivenciar, executar, analisar, fiscalizar e no final obter todo o controle da qualidade, das etapas e posteriormente alcançar os pontos e os resultados positivos para o gerenciamento qualidade do projeto. $\mathrm{O}$ monitoramento é um processo de controle devido aos resultados obtidos, sem esquecer que esse controle e monitoramento são executados no decorrer do projeto. 
O departamento de controle de qualidade identificam os pontos negativos do produto e do fabricante afim de que venham a cumprir a entrega do produto da maneira que a garantia se cumpra ou até mesmo melhorias podem ser discutidas pelo gerente de qualidade do cliente e do fabricante para assim entrarem em um consenso e fazerem um trabalho em paralelo em relação a pontos que podem ser aperfeiçoados.

Auditoria dos requisitos de qualidade e dos resultados das medições do controle da qualidade para garantir que sejam usados os padrões adequados de qualidade e definições operacionais apropriadas. Também inclui a melhoria contínua do processo, meio iterativo de melhorar a qualidade de todos os processos cotidianos no decorrer do projeto. A melhoria contínua de processos reduz o desperdício de tempo e custo como também elimina as atividades que não agregam valor, permitindo que os processos sejam operados com níveis mais altos de eficiência e eficácia (Montes, Eduardo, 2013).

Eduardo Montes retrata tanto o gerenciamento como as ferramentas de qualidade, assim seguindo esses pontos e aplicando teremos a garantia e controle de qualidade do projeto de implantação de complexos eólicos "produtos" terá uma rastreabilidade e uma vida útil mais extensa. O monitoramento e registro dos resultados da execução das atividades de qualidade no setor eólico se deram para avaliar o desempenho e recomendar as mudanças necessárias.

Com todo o controle de qualidade documentada em arquivos contextualizados será mais fácil identificar problemas que não foram sanados no período de implantação do projeto, esses componentes que perante a implantação não foram solucionados, porém ficaram resgistrados em (Check List's e Punch List's) e assim o cliente (Stakeholders) sempre estarão cientes de todas as situações ou problemas que vir a aparecer, pois se tem toda a rastreabilidade representada em relatórios.

\subsection{IMPORTÂNCIA DA QUALIDADE}

A qualidade vem a ser liderada pelo gestor de projeto (PMP) e logo terá todo um passo a passo para atender e cumprir os requisitos legais adotados pelo fabricante, tendo como pontos secundários e paralelos no qual ressalta nas três 
ramificações a serem implantadas e/ou supervionadas, fiscalizadas perante a execução das atividades (Figura 3).

O gerenciamento do setor de qualidade envolve os processos e as tarefas executadas num padrão determinado para cumprirem os objetivos e os interesses no qual forneça e atenda as deficiências ocorridas no decorrer do projeto.

O Project Management Institute - PMI elaborou o Project Management Body of Knowledge - PMBOK (Guia de Conhecimento em Gerenciamento de Projetos), para facilitar especialistas, pessoas capacitadas ou qualificadas e profissionais na parte interagir e gerir projetos.

Figura 3 - Processos da qualidade. Fonte: Santos, F, 2013.

\section{Processos de Gerenciamento da qualidade do projeto}

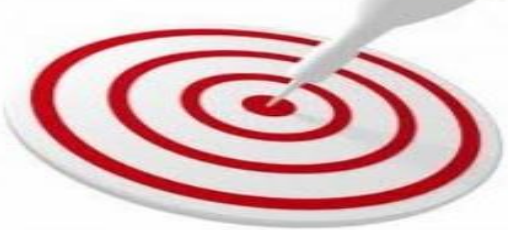

1. Planejar a cualidade 2. Realizar a garantia da Qualidade 3. Realizar o controle da Qualidade

FRANK SANTOS

"A única razão pela qual trabalhamos é a necessidade que alguém tem sobre o resultado do nosso trabalho"

(CAMPOS, 2012)

\subsection{ACOMPANHAMENTO E RESULTADO DA QUALIDADE}

Ao iniciar o projeto o setor de qualidade vem a atuar com todos os pontos que devem ser levantados e supervisionados durante o andamento do projeto e até mesmo retratar evidências através de relatórios de qualidade (Check List's de recebimento de componentes e Punch List's de aceite provisório do produto, relatórios informativos, RAC's - Registros de Avarias de Componentes), com os 
relatórios expedidos para o fabricante devem ser colocados prazos para devidas correções e assim manter o monitoramento e controle da qualidade.

Durante o período de implantação de projetos eólicos, em cima desses pontos terá uma diminuição de perdas de tempo e custos futuros - porém se tem um controle histórico que é criado na construção de projetos eólicos terá uma vida útil do produto mais extensa.

Segundo Juran (2004, p.9), "aos olhos dos clientes, quanto menos deficiências, melhor a qualidade". Contudo, a qualidade é muito mais do que número de deficiências. O bom controle da qualidade permite que a empresa produza de maneira mais assertiva, com redução de custos, de tempo e de desgaste de equipe e material. Afinal, todos estes fatores são repassados de alguma forma ao cliente final.

Uma vez que cliente não tenha sua própria gestão de qualidade, ao final do projeto o cliente terá em Data Books alguns relatos por parte da gestão de qualidade do fornecedor, porém muitas vezes é omitidos problemas do cliente ou até mesmo os colaboradores do fabricante passam por despercebido em alguns pontos importantes, devido por muitas vezes suas terceiras não irem buscar conhecimento em manuais, books de instalação e também não terem pessoas capacitadas e qualificadas para executarem os procedimentos de qualidade apropriados na implantação de projetos eólicos.

\section{IMPORTÂNCIA DO GERENCIAMENTO DE QUALIDADE EM TURBINAS EÓLICAS}

Num projeto eólico é de fundamental importância o conhecimento das 05 etapas fundamentais a serem fiscalizadas no setor de qualidade de implantação de um projeto eólico:

1- Como o produto saiu da fábrica ou local que foi emetido;

De suma importância o cliente fiscalizar como o seu produto sai do local de origem pois as vezes produtos importados ou até mesmo os fabricados no Brasil podem sofrer danos ou falta de material e nas fábricas nem sempre o produto sai 
$100 \%$ apesar de ter o selo da qualidade do fabricante, casos como esses as vezes vem a acontecer, isso implicará na rastreabilidade de como o segmento (componente) saiu e como vai chegar em parque? Se vai estar nos conformes e padrões adequados?

2- Como o produto (componentes) chegou no parque;

Fazer as recepções (inspeções) dos componentes para avaliar e analisar se os componentes chegaram com danos ou até mesmo em condições de não serem montados/ instalados, pois no decorrer da logística eles poderão sofrer danos graves e em alguns casos podem ser condenados pela qualidade do cliente.

Os componentes de grande porte que fazem parte de uma turbina eólica na qual são recepcionadas (inspeção de recebimento do produto) em campo (local do projeto) são:

- Os tramo 1, tramo 2, tramo 3 ou mais tramos pois depende da altura do aero gerador adequado e projetado para o local do projeto;

- Nacelle;

- Hub;

- Pás (Blades)

- Demais segmentos (de pequeno porte) são inspecionados durante a instalação de cada componente.

3- A inspeção dos componentes antes de serem instalados:

Muito importante à fiscalização dos segmentos antes de serem instalados, pois nesse período temos máquinas pesadas e muito movimento nos WTG's ou PAD's (Wind Turbine Generator) no pátio onde ficam os componentes durante a instalação e assim muitas vezes acontecem danos nos componentes e isso impacta que o fabricante procura omitir do cliente devido a perca de tempo de ter de emitir o procedimento que será executado dependendo do dano e o relatório final no qual foi executado sobre o dano apontado. 
4- A inspeção do aero gerador com toda parte eletromecânica instalada:

Essa inspeção nos servirá para o aceite provisório de energização, pois será feito um tipo de relatório que resultará numa lista de pendência (Punch List), pendências essas não impeditiva de energização com prazo de retirada, essa lista de falhas encontradas deverão ser sanadas após a operação assumir, geralmente essas pendências vão sendo retiradas nas manutenções de O\&M (Operação e Manutenção), ou seja, nas manutenções programadas, por isso é importante a ratreabilidade da parte do setor de qualidade pois a maioria dos problemas que venham a impactar em paradas inorportunas, custos e tempo é detectado no período de instalação e arquivado em documentos de fiscalização.

5- Esse ponto é muito importante se resume na reinspeção:

É uma segunda inspeção do aero gerador para realizar e analisar a retirada das pendências apontadas no Punch List de cada aero gerador conforme ressaltado no ponto 4 acima. Apesar de serem pendências leves ou médias, devem ser sanadas pelo fabricante pois esses pontos podem ao longo do tempo se tornarem graves, ex.: pontos de oxidações, pinturas não conformes, ou seja, pinturas sem está no RAL correto.

Enfim seria a inspeção final da implantação do projeto eólico, porém conforme ressaltado neste trabalho o cliente entra em acordo com o fabricante para as pendências apontadas serem sanadas no decorrer da manutenção do parque. Em cima de todas as etapas do setor qualidade o gerente do projeto consegue planejar a qualidade, realizar a garantia da qualidade do produto e realizar o controle da qualidade do projeto.

Neste trabalho todos os relatos acima o gerente de projeto supervisiona o setor de qualidade por parte dos Stakeholders (Cliente) fazendo com que o fabricante atue de maneira e procedimentos corretos de instalação. A fiscalização aconteceu num complexo eólico que contemplava 105 turbinas eólicas de dois Megawatts implantados totalizando $210 \mathrm{MW}$ na região do Araripe em Simões-PI em 2015, a fiscalização nesse projeto foi considerada em cima de todos os processos de qualidade, pois foram presenciadas instalações fora dos padrões na parte das inspeções dos aero geradores, sempre buscando a Garantia do produto/ Controle da 
qualidade, esse controle se dá a partir do ponto de equiparação aos procedimentos aceitáveis executados em campo ao manual de instalação dos aeros. No final do acompanhamento do projeto de grande porte verificou-se melhorais e atuações de montagem dos aero geradores, pois boa parte da instalação estava fora do padrão de instalação e até mesmo melhorias aconteceram, pois os inspetores juntos com seus supervisores passaram a analisar, trazendo melhorias ao próprio fornecedor como também o cliente. Esse acompanhamento tornou-se para o projeto pontos positivos (esteticamente, durabilidade e rastreabilidade do produto e vida útil do produto), atendendo a forma correta de alguns procedimentos de instalação. No entanto esse otimismo obtido na parte da qualidade durante o projeto se deu pela gerência da qualidade.

As etapas do projeto foram sequenciadas, por plano de gestão de qualidade, plano de segurança do produto e monitoramento da qualidade. Todos esses processos apontados na (Figura 3) é de fundamental importância, contudo esses processos foram liderados pelo Project Manager no decorrer do desenvolvimento de implantação do projeto. Dentre os pontos fiscalizados em projetos passados em 2015 (Simões-PI) e 2016 (Parazinho-RN) foi percebido em reuniões que muitas tratativas e providências foram tomadas e com novas definições e procedimentos diferentes na qual atendia as normas da ABNT perante há novos projetos (Itarema$\mathrm{CE}$ ), até mesmo mudanças de planta (fábrica) de alguns componentes que compõe o aero gerador, ou seja, pontos fundamentais que foram discutidos a nível dos setores de qualidade tanto o da parte do cliente como do fabricante, pontos de melhorias alinhados entre as empresas e atualmente com essas melhorias deixaram de ocasionar paradas inoportunas e uma melhor eficiência do aero gerador, além do mais o fabricante reduziu bastante o número de pendências, melhorando no custo benefício na qual eram apontados nesses projetos, e assim trazendo uma melhor aceitação da turbina eólica CAP (Certificação de Aceitação Provisória) para atender o mínimo das condições para liberar energização de cada aero gerador e também o cliente ficou bem mais satisfeito em relação a projetos anteriores vivenciados.

Neste projeto vê-se a importância de conhecer todas as falhas que foram apontadas a fim de serem solucionadas durante o projeto e baseando em projetos anteriores com o mesmo fabricante fortaleceu o vinculo da melhoria de componentes de aero geradores conforme aplicações feitas junto as empresas contratadas pelo 
fabricante. Temos um só objetivo - Permanecer no ponto de uma consultoria bem sucedida como também com o ganho futuro em cima de custo/tempo perdido na operação do projeto eólico. As fiscalizações e auditorias de qualidade indicarão sinais positivos ao projeto, principalmente ao cliente, entretanto o esforço garantido no processo de implantação demonstrarão melhorias para o fornecedor.

\subsection{REPRESENTAÇÕES E DADOS DE PROBLEMAS ENCONTRADOS}

O complexo eólico Ventos do Araripe I é composto por 105 aeros, divididos em 7 parques de 15 aeros cada, com uma potência total instalada de $210 \mathrm{MW}$ :

- ONFRE I, II e III;

- JOANA II, VI, VIII e XIV;

Dentre os parques mencionados acima um dos parques foram encontrados um maior número de pendências, na qual era um projeto de muitas turbinas eólicas e nos últimos aeros muitas peças faltam, somem do projeto e as últimas máquinas ficam um pouco sucateadas por falta de itens, objetos e etc. Isso implica quando o cliente vai receber (inspeção do cliente) o aero para ser energizado e logo entrar em operação vai ter um número de pendências bem maior.

Consideramos dois pontos críticos:

1- No parque JOANA VI com 455UND (pendências) num total dos 15 aero geradores tendo em média um número de $\cong 30,3$ pendências/ turbina, contendo um maior número de pendências entre os demais parques (Figura 4), todas as pendêcias apontadas na lista de pendências feita por cada aero gerador, foi discutido entre a qualidade do cliente e a qualidade do fabricante na qual apresentava procedimentos, onde se tornava aceitável ou não, pois em muitos pontos tem de ser julgado forma correta em cima das normas brasileiras, e também alguns pontos foram apontados na qual poderia ser feito melhorias, no entanto muitas pendências apontadas foram sanadas no perídodo de O\&M ( Operação e Manutenção). 
2- Outro ponto crítico, é o site com maior porcentagem de pendências graves, que é o ONOFRE II com 37\% (Figuras 4 e 5);

Figura 4 - Gráfico representativo de pendências JOANA VI. Fonte: Santiago, J. 2015

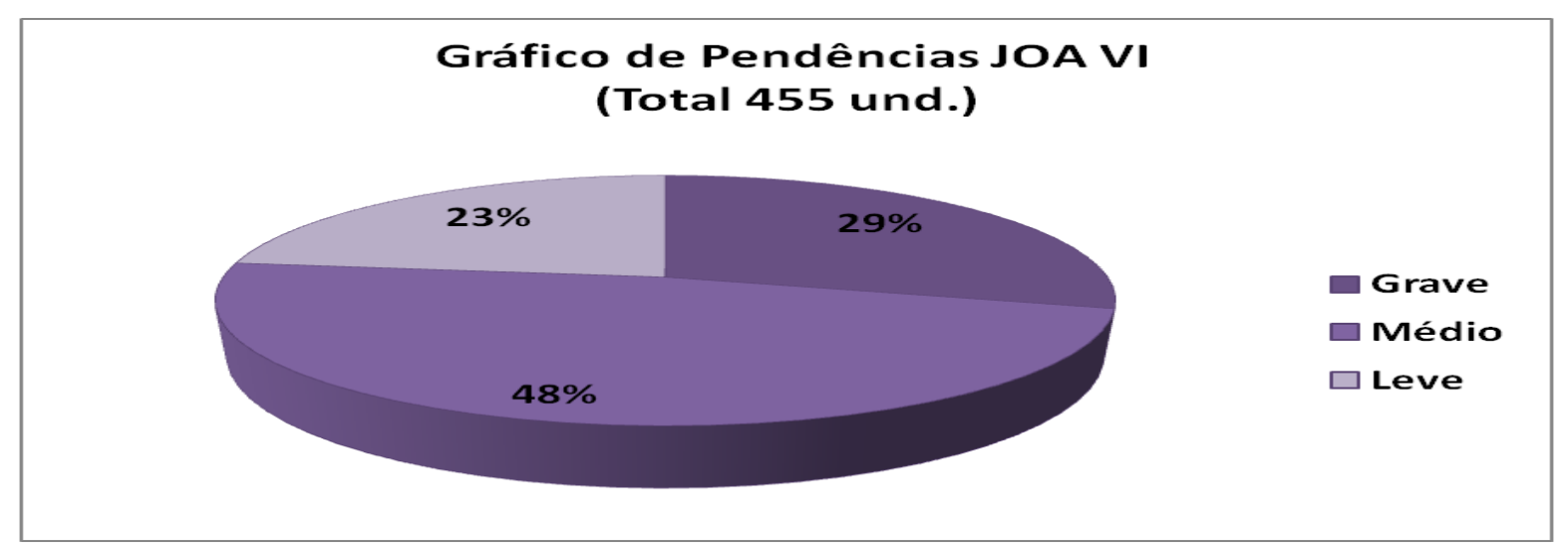

Figura 5 - Gráfico representativo de pendências ONOFRE II. Fonte: Santiago, J. 2015

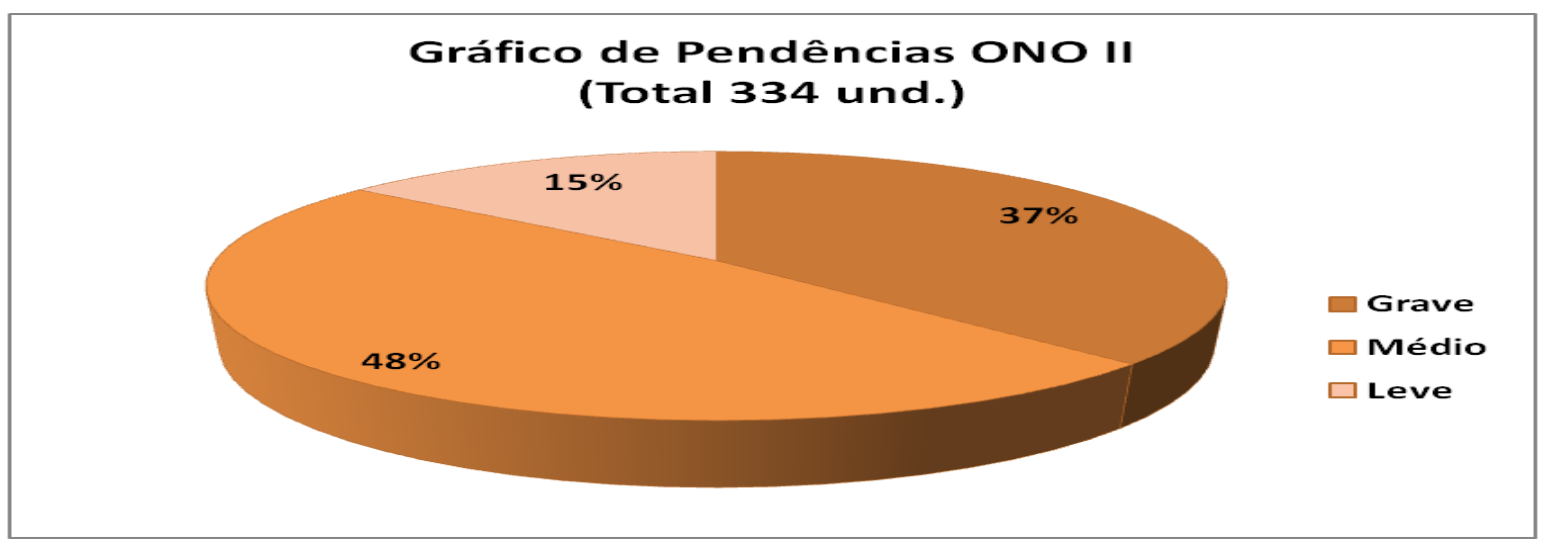

3- Na tabela sequente segue um exemplo de cada um dos sites e um AEG - Aero gerador com as respectivas pendências e gravidade apontadas;

\begin{tabular}{|c|c|l|c|}
\hline \multicolumn{1}{|l|}{ Pendências Ventos do Araripe } & \multicolumn{1}{|c|}{ Descrição } & Gravidade \\
\hline Site & AEG & \multicolumn{1}{|c|}{ Grave } \\
\hline ONOFRE I & $\mathbf{0 1}$ & Grout danificado no T1 & Médio \\
\hline ONOFRE II & $\mathbf{0 3}$ & $\begin{array}{l}\text { Pintura do segmento não de acordo com procedimentos não } \\
\text { seguia o mesmo RAL }\end{array}$ & Leve \\
\hline ONOFRE III & $\mathbf{0 6}$ & T1 precisa de limpeza & Grave \\
\hline JOANA II & $\mathbf{0 5}$ & Parafuso do Terra encontra-se fora de padrão de marcação & Médio \\
\hline JOANA VI & $\mathbf{1 0}$ & Aterramento interno não conectado & Leve \\
\hline JOANA VIII & $\mathbf{0 7}$ & Melhorar aplicação dos adesivos de sinalização internos & Grave \\
\hline JOANA XIV & $\mathbf{0 4}$ & Cabos da RMT em quinas sem proteção, podendo causar danos & \\
\hline
\end{tabular}




\section{CONCLUSÕES}

$\mathrm{Na}$ implantação de projetos eólicos é fundamental o acompanhamento e fiscalização do produto comprado desde a saída da fábrica até o componente instalado, na qual se adquirem as rastreabilidades compostas em relatórios. Se a gestão de qualidade não se impor poderá ter problemas a partir do início implantação do projeto - atrasos, custos futuros e paradas inoportunas.

A gestão de qualidade em complexos eólicos foi baseada em documentos de aceitação do produto CAP da torre eólica (Certificado de Aprovação Provisória), buscando todos os procedimentos plausíveis que contempla na construção de complexos eólicos.

Em virtude dos termos mencionados conclui-se que a gestão de qualidade na implantação de projetos eólicos é de fundamental importância, pois os Stakeholders terá conhecimento de todos os problemas relatados formalmente em relatórios e tendo uma garantia e vida útil do produto estendida.

Nos dias atuais, um gestor com toda sua arbitrariedade no setor de qualidade têm de impor seriedade e continuidade aos problemas encontrados de padrões não cumpridos pelo fabricante, falta das execuções das normas de qualidade, pois dificuldades serão presenciadas e assim devem solucionar os problemas e atingir as metas a cumprir tempo, custos e qualidade.

O setor de qualidade tem de contemplar uma rastreabilidade, deixar todas as evidências para um acompanhamento e monitoramento futuro do complexo eólico implantado (Stakeholders O\&M - Operação e Manutenção), pois os problemas apresentados durante a instalação podem influir negativamente como paradas inoportunas e perdas de geração.

Nesse artigo foram apresentadas maneiras de contemplar um projeto com tempo hábil sem recriminar a qualidade do fabricante trazendo benefícios. Toda essa consolidação adquirida se dá através da gestão de qualidade do projeto envolvendo os pontos de procedimentos de instalação acompanhados, a fim de deixar resultados positivos: evitar perda de tempo e custos futuros. 


\section{REFERÊNCIAS BIBLIOGRÁFICAS}

OAKLAND. J. S. - Gerenciamento da Qualidade total - $1^{\text {a }}$ edição. São Paulo: Editora Nobel, 1994.

DUTRA, R. D. - Centro de Referência para Energia Solar e Eólica Sérgio de Salvo Brito - Energia Eólica "Princípios e Tecnologias". CRESESB, CEPEL, 2008.

SANDIA. Vertical Axis Wind Turbine: The History of the DOE Program.

Disponível em http://www.sandia.gov/Renewable Energy/wind energy/topical.htm. Arquivo consultado em 16-03-2017.

PMI - PROJECT MANAGEMENT INSTITUTE PMBOK - Um guia do Conjunto de Conhecimentos em Gerenciamento de Projetos. $5^{\mathfrak{a}}$ edição. Pennsylvania, USA: Project Management Institute, 2013.

CIERCO, A. ROCHA, A. MOTA, E. JUNIOR, I. AMORIM, S. Gestão da Qualidade. $10^{\underline{a}}$ ed. Gestão Empresarial. Rio de Janeiro: FGV Editora, 2010.

MONTES, E. Plano de gerenciamento da qualidade. [atualizado em 2016 Dez 27, citado em 2017 Mai 17] Disponível em: https://escritoriodeprojetos.com.br/artigos-degerenciamento-da-qualidade Arquivo consultado em 18-03-2016.

MELO, P.P.O. Gestão da Qualidade - Processo. 2006. In: PÓS GRADUAÇÃO E APERFEIÇOAMENTO EM GERENCIAMETO DE PROJETOS. 2006. IETEC.

SOUZA, R. et al. Sistema de Gestão da Qualidade para Empresas Construtoras. São Paulo. PINI. 1995. 247p.

JURAN, J. M. A qualidade desde o projeto: Os novos passos para o planejamento da qualidade em produtos e serviços. São Paulo: Pioneira, 1992.

DEMING, W. E. Qualidade: a revolução da administração. São Paulo: Marques Saraiva, 1990.

ANTÔNIO, N. T. A. Gestão da Qualidade De Deming ao Modelo de Excelência da EFQM. Lisboa: Ediçõs Sílabo, 2009.

CAMPOS, F. V. Gerenciamento da rotina do trabalho do dia-a-dia. [citado em 2012 Out 12] Disponível em: http://www.trabalhosfeitos.com/ensaios/GerenciamentoDa-Rotina-Do-Trabalho-Do/434316.html. Arquivo consultado em 17/05/2017

SANTOS, F. Gerenciamento da qualidade do Projeto. [citado em 2013 Dez 13] Disponível em: https://pt.slideshare.net/ibnshekinah/processo-de-gerenciamento-daqualidade-pmbok slide 2. Arquivo consultado em 14/05/2017 